\title{
COMO CRIAR E CLASSIFICAR CATEGORIAS PARA FAZER ANÁLISE DE CONTEÚDO: UMA QUESTÃO METODOLÓGICA ${ }^{1}$
}

\author{
Márcio C. Carlomagno² \\ Leonardo Caetano da Rocha ${ }^{3}$
}

\begin{abstract}
Resumo: O objetivo deste artigo é apresentar a metodologia de análise de conteúdo, a partir de uma revisão e sistematização da literatura norte-americana fundadora da área. Resumem-se cinco regras que orientam a etapa de criação e classificação de categorias coerentes de análise: 1) devem existir regras claras de inclusão e exclusão nas categorias; 2) as categorias precisam ser mutuamente excludentes; 3 ) as categorias não podem ser muito amplas, sendo seu conteúdo homogêneo entre si; 4) as categorias devem contemplar todos conteúdos possíveis e "outro" precisa ser residual; 5) a classificação deve ser objetiva, não passível de ser codificada de forma diferente a depender a interpretação do analista. Ao fim, discutimos o equilíbrio entre comparabilidade e adaptabilidade na criação de categorias. A relevância do artigo está em sistematizar os aspectos desta metodologia para pós-graduandos interessados em conduzir estudos com tal técnica.
\end{abstract}

Palavras-chave: análise de conteúdo; metodologia política; categorias; classificação; Harold Lasswell; comunicação política.

Abstract: The purpose of this article is to present the content analysis methodology, based on a review and systematization of American literature, founder of this area. We summed up five rules that guide the project planning stage, in particular the creation of coherent categories of analysis: 1) there must be clear inclusion and exclusion rules in the categories; 2) categories must be mutually exclusive; 3) the categories can not be too broad, and its homogeneous content; 4) categories shall include all possible contents and "other" must be residual; 5) the classification should be objective, not likely to be coded differently depending on the interpretation of the analyst. After, we discuss the balance between comparability and adaptability in creating categories. The relevance of this paper is to systematize aspects of this methodology for graduate students interested in conducting studies with this technique.

Keywords: content analysis; political methodology; categories; classification; Harold Lasswell; political communication.

Resumen: El propósito de este artículo es presentar la metodología de análisis de contenido, basado en una revisión y sistematización de la literatura fundadora americana. Resumió cinco reglas que guían la etapa de creación de categorías coherentes de análisis: 1) no debe haber reglas de inclusión y exclusión claros en las categorías; 2) categorías deben ser mutuamente excluyentes; 3) las categorías no pueden ser demasiado amplia, y su contenido homogéneo entre sí; 4) categorías se incluyen todos los contenidos posibles y "otros" deben ser residual y 5) la clasificación debe ser objetiva, no es probable que ser codificados de manera diferente dependiendo de la interpretación del analista.. También discutimos el equilibrio entre comparabilidad y la adaptabilidad en la creación de categorías. La relevancia de este trabajo es sistematizar los aspectos de esta metodología para estudiantes graduados interesados en la realización de estudios con esta técnica.

Palabras clave: análisis de contenido; metodología política; categorías; clasificación; Harold Lasswell; comunicación política.

\section{INTRODUÇÃO}

Este artigo metodológico pretende proceder com uma síntese explicativa sobre o que é análise de conteúdo e, em específico, como criar categorias analíticas para aplicação neste tipo de pesquisa. O objetivo deste artigo é didático, não trazer novas evidências, abordagens ou aplicações do método 4 . Embora talvez pareça introdutório àqueles experienciados na área, tal conteúdo é destinado a pós-graduandos e estudantes recém-iniciados na pesquisa científica, em metodologia política ou na metodologia específica - e este é o público-alvo ao qual se destina. O objetivo do presente artigo é, portanto, ser um guia prático para jovens

\footnotetext{
${ }^{1}$ Agradecemos aos pareceristas anônimos da Revista Eletrônica de Ciência Política pelas sugestões e contribuições, bem como ao fundamental trabalho do corpo editorial desta revista.

${ }^{2}$ Mestre e doutorando em Ciência Política pela Universidade Federal do Paraná (PPGCP-UFPR). Bolsista Capes. Contato: mccarlomagno@gmail.com

${ }^{3}$ Mestre e doutorando em Ciência Política pela Universidade Federal do Paraná (PPGCP-UFPR).Contato: 1rocha_87@yahoo.com. br

${ }^{4}$ Para novas abordagens sobre o método, veja Hopkins \& King (2010).
} 
pesquisadores $^{5}$.

As ciências sociais em geral e a ciência política em específico sofrem no Brasil de uma deficiência endêmica de falta de compreensão sobre os seus métodos de análise (SOARES, 2005), embora tenhamos feito grande progresso nas últimas décadas (BARBERIA, GODOY, BARBOZA, 2014; NEIVA, 2015). Ainda hoje um problema da ciência política no Brasil é a falta de compreensão mais intensa sobre métodos.

A metodologia de análise de conteúdo foi destacadamente desenvolvida durante a Segunda Guerra Mundial $^{6}$, pela "Divisão experimental para o estudo de comunicações em tempos de guerra", do Congresso dos Estados Unidos, sob coordenação de Harold Lasswell. A metodologia foi criada especialmente para sintetizar e compreender o conteúdo dos argumentos utilizados por jornais e propagandas inimigos, e, somente após isso, passou a ter aplicação em estudos acadêmicos de comunicação política. Logo após o fim da guerra, foi lançado e tornou-se clássico o livro "The language of politics: studies in quantitative semantics" ", cuja tradução chegou quase 40 anos depois ao Brasil, sem o seu subtítulo ("estudos em semântica quantitativa", em tradução livre). Kimberly Neuendorf, autora de um dos mais importantes handbooks contemporâneos sobre análise de conteúdo, definiu Lasswell ${ }^{8}$ como "muito possivelmente a figura mais influente do século XX no desenvolvimento do estudo sistemático de mensagens" (NEUENDORF, 2002, p. 32, tradução livre) ${ }^{9}$ e "o da Vinci das ciências comportamentais" (NEUENDORF, 2002, p. 34, tradução livre). É importante ressaltar, portanto, de antemão, o valor instrumental da metodologia ${ }^{10}$, criada para uma aplicação prática ${ }^{11}$ e só depois vastamente adotada pela academia.

Esta metodologia tem sido especialmente relevante para pesquisadores na área da comunicação social, jornalismo, marketing, mídias sociais e correlatas, embora não apenas. Em fato, a análise de conteúdo pode ser realizada sobre qualquer tipo de ato enunciativo (mensagem), por qualquer meio.

Uma etapa específica do processo global de análise de conteúdo é a fase de planejamento, coleta e sistematização dos dados (e, certamente, uma das mais importantes). As demais fases de cunho analítico dependem de uma coleta realizada de modo adequado. Por isso este artigo aborda um dos aspectos centrais desta fase, não a análise de resultados propriamente dita ou o desenho de pesquisa ${ }^{12}$. Em específico, como criar

${ }^{5}$ Para mais, além dos clássicos tratados aqui, dois bons artigos são Oliveira (2008) e Moraes (1999).

${ }^{6}$ Embora algumas incursões iniciais já existissem desde os anos 1920, para estudo das comunicações comunistas.

${ }^{7}$ Outro clássico fundador da área é Bernard Berelson (1952), Content analysis in communication research, que não iremos tratar aqui.

${ }^{8}$ Para quem desejar saber mais sobre Lasswell, em português, uma alternativa é Carvalho (2012).

${ }^{9}$ No original: "very possible the single most influential figure in the development of the systematic study of messages in the $20^{\text {th }}$ century"

${ }^{10}$ É o próprio Lasswell quem faz questão de ressaltar este aspecto instrumental da metodologia: "vale notar que os meios quantitativos para descrever a atenção prestam-se a fins muito práticos, além dos científicos. Um dos problemas mais cruciais na condução da guerra consiste em prever as ações do inimigo. O setor de informações de qualquer Estado-Maior ou agência de operações está permanentemente envolvido numa luta de cérebros com o inimigo, cujo objetivo é prever suas ações militares, diplomáticas, econômicas e propagandísticas antes que ele as execute, bem como avaliar em que ponto um ataque pode causar-lhe maiores prejuízos. Para tal fim, uma das importantes fontes de informação consiste naquilo que o inimigo dissemina através de seus canais de comunicação.” (LASSWELL, 1982a [1949], p. 46)

${ }^{11}$ Um exemplo de tal aplicação foi a utilização deste recurso para condenação de "inimigos internos" durante a Guerra. Lasswell começa um artigo pragmaticamente narrando o fato que, segundo ele, demonstrava a importância da metodologia: “Tem-se aceito como provas, nos tribunais federais norte-americanos, fatos determinados através da análise de conteúdo. Em todos os casos, o problema submetido à justiça consistia na detecção de propaganda em um veículo de comunicação pública. O Departamento de Justiça fundamentou-se parcialmente em estudos quantitativos de conteúdo ao apresentar os argumentos do Governo" (LASSWELL, 1982b [1949], p. 163). Fica evidente sua preocupação de ciência aplicada, inclusive para fins forenses, não somente abstrata, e por isso a necessidade de profundo rigor metodológico.

${ }^{12}$ Para chegar até o momento do qual trata este artigo, você deve ter passado por algumas etapas lógicas, um tanto óbvias: a) saber o que deseja pesquisar, ter definido seu objeto e recorte temporal. b) saber como a verificação do conteúdo que você irá fazer poderá 
categorias lógicas e coerentes para a análise.

A partir disto, muitos e substancialmente diferentes estudos podem ser produzidos, com basicamente a mesma fonte de dados. Podem ser produzidas análises descritivas, que se proponham a descrever o comportamento do objeto, ou podem ser utilizadas técnicas mais sofisticadas, como análise de correspondência (CAMPOS, 2014), técnicas de tratamento de dados categóricos (CERVI, 2014; BURNS \& BURNS, 2008), entre outros. Esta fase não será abordada aqui.

Na próxima seção, apresentamos o que é análise de conteúdo e, na seguinte, sintetizamos em cinco regras os aspectos fundamentais a serem seguidos para criar e classificar corretamente categorias para realizar uma análise de conteúdo bem-sucedida.

A abordagem apresentada aqui não é a única existente. Na literatura brasileira, usualmente artigos que utilizam análise de conteúdo fazem referência a Bardin (2011 [1977]), o prefereti dos sociólogos brasileiros. A despeito disto, defendemos aqui nos atermos à perspectiva norte-americana, que é, de fato, o clássico fundador desta área. Acreditamos que este status de citação quase unânime de Bardin é superestimado ${ }^{13}$. Não há praticamente nada nesta autora que já não estivesse em Lasswell e em seus co-autores e colegas de pesquisa - ou nos metodólogos norte-americanos. Já temos, portanto, os aspectos fundamentais de que precisamos com as lições ensinadas pelos fouding fathers desta metodologia, bem como pelos atuais ${ }^{14}$ metodólogos que os seguiram.

\section{O QUE É ANÁLISE DE CONTEÚDO?}

A metodologia de análise de conteúdo ${ }^{15}$ se destina a classificar e categorizar qualquer tipo de conteúdo, reduzindo suas características a elementos-chave, de modo com que sejam comparáveis a uma série de outros elementos. Como Irving Janis sintetiza, em capítulo do célebre livro organizado por Harold Lasswell e Abraham Kaplan:

A análise de conteúdo fornece meios precisos para descrever o conteúdo de qualquer tipo de comunicação: jornais, programas de rádio, filmes, conversações quotidianas, associações livres, verbalizadas, etc. As operações da análise de conteúdo consistem em classificar os sinais que ocorrem em uma comunicação segundo um conjunto de categorias apropriadas. (JANIS, 1982 [1949], p. 53)

Vale destacar desta citação de Janis dois elementos centrais desta prática: a ideia de classificação e de categorias apropriadas. O que são categorias apropriadas e o que as constitui como tal será abordado na

confirmar ou negar suas hipóteses. Estas etapas fazem parte da metodologia de pesquisa em sentido muito mais amplo, por isso não nos deteremos nelas. Sabendo que você quer investigar o conteúdo de algo (o tipo de artigo publicado numa revista; os temas mais abordados por um candidato em uma campanha; as notícias em destaque em um jornal ou o que for), como fazer isso? Como criar categorias funcionais para isso?

${ }^{13}$ Acreditamos que a aderência dos sociólogos brasileiros a Bardin, na segunda metade do século XX e que permaneceu até hoje, pode ser atribuída, ao menos em parte, ao desejo de não alinhar-se com um analista norte-americano, em um contexto de polarização ideológica, uma vez que Lasswell trabalhou para o governo dos Estados Unidos, com finalidades políticas.

${ }^{14}$ Dar os créditos a quem os merece, isto é, aos criadores da metodologia, não implica negar a importância fundamental de novas técnicas surgidas nas últimas décadas, em especial, os aspectos estatísticos e abordagens computacionais que estão promovendo uma verdadeira revolução no campo.

${ }^{15}$ É importante não confundir análise de conteúdo com análise do discurso. Esta última é uma abordagem filosófica que busca compreender a origem dos enunciados, sua inserção em dados contextos e a produção de significados. Possui nas correntes russa (BAKHTIN, 2006) e francesa (PÊCHEUX, 2009) seus principais baluartes. Algumas pessoas utilizam o termo "análise de conteúdo do discurso", para análises de conteúdo aplicadas, por exemplo, a discursos políticos. Esta é uma redundância desnecessária, já que a análise de conteúdo é feita para ser aplicada em quaisquer mensagens, incluso "discursos", genericamente falando. 
seção seguinte deste artigo.

Janis argumenta que, entre as destinações possíveis de uma pesquisa que se valha da análise de conteúdo, estão três tipos de estudos, que busquem "determinar as relações entre uma determinada característica (conteúdo) das comunicações e (a) as características do comunicador, (b) as características da audiência, ou (c) alguma outra característica (de conteúdo ou não) da comunicação.” (JANIS, 1982 [1949], p. 53). Apenas para ilustrar, podemos pensar em aplicações hipotéticas para as três destinações elencadas por Janis. Exemplos disto poderiam ser: (a) a comparação entre dois ou mais políticos/candidatos e os temas sobre os quais cada um deles mais tratou; (b) a relação entre as características de produções midiáticas e o consumo das mesmas, estratificado por países, classe social, gênero, região etc; (c) a relação entre a menção a determinado candidato e o enquadramento $\mathrm{X}$ ou $\mathrm{Y}$, durante a cobertura eleitoral por parte da imprensa.

A metodologia tem uma extensa lista de aplicações no plano da comunicação social. Um de seus próceres no Brasil foi Marcus Figueiredo, que, coordenando o DOXA do antigo IUPERJ (hoje IESP), utilizou a metodologia para analisar as valências ${ }^{16}$ da cobertura da imprensa durante eleições (ALDÉ, MENDES, FIGUEIREDO, 2007; FIGUEIREDO, ALDÉ, MENDES, 2007; CERVI \& MASSUCHIN, 2013).

Em campanhas eleitorais, análise de conteúdo já foi utilizada para mensurar estratégias argumentativas adotadas pelos candidatos, tanto, tradicionalmente, no HGPE (FIGUEIREDO, ALDÉ, JORGE,. 1997; CERVI, 2011; CERVI, MASSUCHIN, TAVARES, 2012), quanto analisar websites de partidos políticos (GIBSON \& WARD, 2000; VACCARI, 2008; SILVA, 2012) e, mais recentemente, estudar candidatos e políticos nas mídias sociais (RECUERO, ZAGO, BASTOS, 2014; AGGIO, 2015; BRAGA, NICOLÁS \& BECHER, 2013; BRAGA, ROCHA \& CARLOMAGNO, 2015; ITUASSU \& LIFSCHITZ, 2015). Pode ser utilizada desde para análise de distintos estilos de representação política (JACKSON, LILLEKER, 2011.LILLEKER, KOC-MICHALSKA, 2013) até para estudos sobre comportamento político e deliberação (SAMPAIO, BARROS, MORAIS, 2012; SAMPAIO, 2012). Na comunicação, pode ser usada tanto em estudos sobre produção de conteúdo, quanto para categorizar distintos tipos de recepção.

Embora a análise de conteúdo seja muito utilizada em comunicação social, não está restrita a esta área. Ela tem sido muito empregada na análise de política externa e de relações internacionais, por exemplo, com a aplicação em pronunciamentos oficiais para compreender a política externa brasileira (VILELA \& NEIVA, 2011; SILVA, RIBEIRO E CARVALHO, 2015). Assim como é utilizada também na análise documental (PIMENTEL, 2001), de administração e marketing (MADEIRA et al, 2011) ou mesmo em revisões bibliográficas. Figueiredo Filho et al (2014) propõem um instigante método para uso de meta-análise em revisões de literatura. Para isso, categorizam uma série de elementos desta literatura. Ou seja, mesmo para aquilo que historicamente era visto por alunos como um trabalho de fichamento de uma obra literária, pode-se utilizar análise de conteúdo e métodos estatísticos sofisticados para identificar distinções. Fernando Leite (LEITE, 2010, 2015; LEITE \& CODATO, 2013) é outro excelente exemplo de como análise de conteúdo pode ser aplicada em áreas outras que não a comunicação social. Neste caso, o autor analisou e classificou as características encontradas nos artigos publicados pelas revistas brasileiras mais importantes na área da ciência política em relação a uma série de elementos (como abordagem metodológica, enfoque teórico, etc), demonstrando os padrões de proximidade entre os elementos pesquisados. Também Nicolás, Bragatto e Sampaio (2013) procederam com análise de conteúdo de literatura, mas em relação aos artigos da área de comunicação social. Em fato, análise de conteúdo vai além das próprias ciências sociais, sendo aplicada também em áreas tão distintas quanto enfermagem e educação (DOWNE;WAMBOLDT, 2009). Análise de conteúdo pode existir, em

\footnotetext{
${ }^{16}$ Importante não confundir: embora a análise de valência utilize um tipo de análise de conteúdo, estas não são sinônimos. Para quem quiser saber mais sobre valências, vale conferir o eletrizante debate entre Miguel (2015), Feres Júnior (2016) e Miguel (2016). 
seu sentido mais amplo, mesmo quando não chamada por este nome, como, por exemplo, em estudos sobre o conteúdo substantivo de propostas de leis, como em Mesquita et al (2014).

Em comum em todas estas pesquisas, há uma característica que é importante ressaltar. A questão é quanto à natureza deste tipo de análise. Ela é quantitativa, a despeito de equívocos reiterados acerca desta questão. ${ }^{17}$ Justamente por trabalhar com características e qualidades dos conteúdos, é comum a tentação de alguns chamarem isto de uma análise "qualitativa" 18 . Especialmente porque em certos flancos da academia brasileira (na área de humanas) existe resistência e até preconceito contra o termo quantitativo. Algumas pessoas podem achar que quantitativo refere-se somente àquilo que mede apenas e tão somente quantidades (como a frequência simples do número de curtidas em uma página do Facebook ou do número de matérias publicadas por um jornal) e que, quando se coletam dados que se referem a qualidades, como, por exemplo, o viés positivo ou negativo de matérias jornalísticas, os assuntos/temas de um programa televisivo ou os argumentos utilizados em algum meio, então, por se referirem a qualidades deste objeto, o estudo seria qualitativo. Não é.

Como dois autores clássicos deixam claro: "os procedimentos de análise de conteúdo resolvem adequadamente o problema de descrever o quadro de atenção em termos quantitativos." (LASSWELL, 1982a [1949], p. 46) e "uma característica que distingue a análise de conteúdo das outras técnicas descritivas das comunicações é o seu aspecto quantitativo." (KAPLAN \& GOLDSEN, 1982, p. 77). Como se percebe, segundo Kaplan \& Goldsen, ser quantitativa é a própria definição da natureza da análise de conteúdo - isto para não mencionar que o próprio título do artigo (“Por que ser quantitativista?") de Lasswell já indica seu argumento 19.

Em fato, cabe deixar claro: a designação se seu método é quantitativo ou qualitativo se refere a como você sistematiza os dados com os quais trabalha, não a natureza de sua análise. Não importa que, por exemplo, ao identificar os argumentos presentes em determinada mensagem, você esteja verificando "qualidades" deste objeto. Se você sistematiza (e de alguma forma quantifica) estas informações em uma planilha, banco de dados ou em uma folha de caderninho, esta pesquisa é, portanto, quantitativa-categórica.

\section{COMO CRIAR CATEGORIAS}

Da citação de Janis apresentada na seção anterior destacamos o conceito central de categorias apropriadas, fundamental para a prática da análise de conteúdo. Mas o que são categorias apropriadas? O que as constitui como tal?

${ }^{17}$ Como já salientamos, esta é a abordagem aqui defendida, a partir do recorte dos autores tratados, não a única existente, remanescendo um longo debate sobre a questão nas ciências sociais. Veja Riffe, Lacy \& Fico (2005), para uma defesa recente sobre a natureza quantitativa deste tipo de análise.

18 Parece ser demasiadamente longa a lista de autores que insistem em chamar análise de conteúdo de "qualitativa". Entre eles, podemos citar: Mozzato \& Grzybovski, 2011; Silva, Gobbi e Simão, 2005; Moraes, 1999; Caregnato \& Mutti, 2006. Vale pontuar que por vezes a análise de conteúdo recebe o nome "qualitativo" por motivos distintos. Nas ciências sociais, a confusão se deve em parte por uma invenção de Bardin, para quem a análise de conteúdo quantitativa seria apenas aquela que trabalhasse com frequência, ao passo que a que associasse diferentes categorias seria qualitativa (BARDIN, 2011 [1977], p. 144-146). Apesar da falta de lógica (e da evidente falsidade, à luz da explicação da Janis), tal citação é vastamente repetida por seus seguidores. Já no campo da economia, administração e correlatos (como Silva \& Fossá, 2013), o termo "qualitativo" é usado em contraposição à "quantitativo" em sentido estrito, que refere-se tão somente a valores contínuos. Este uso é compreensível e até justificável. Em fato, o termo mais tecnicamente correto não seria nem qualitativo nem quantitativo, mas, como utilizado por Oliveira (2008), "análise categorial” ou "análise categórica" (embora também esta autora chame de "qualitativo"). Isso se deve porque se utilizam categorias para compor a análise. Estas categorias são quantificáveis, portanto, é uma análise quantitativa. Contudo, elas não são escalas contínuas (como um índice que vai de zero a um), não sendo aplicáveis a elas o mesmo tipo de tratamento estatístico usado para dados numéricos puros.

${ }^{19}$ Apesar de Lasswell defender suas posições, é importante pontuar que ele não é um sectário como alguns pregam a seu respeito. O próprio reconhece a necessidade e o espaço também para análises teóricas e não quantitativas: "Isto não implica, obviamente, que os métodos não-quantitativos devam se abandonados. Pelo contrário, há necessidade de uma teoria mais sistemática e de "intuições" mais inspiradas a fim de aproveitar na prática as potencialidades plenas da precisão. Como o revela a história da quantificação (na economia, por exemplo), ocorre uma interação permanente e proveitosa entre teoria, intuição, impressão e precisão." (LASSWELL, 1982a [1949], p. 48) 
Existem algumas regras fundamentais que precisam ser seguidas em uma pesquisa que utilize análise de conteúdo, especialmente ao criar as categorias com as quais você vai trabalhar. Estas mesmas regras lógicas valem, também, para a criação de categorias em termos mais gerais, para quaisquer estudos, ainda que não aplicadas à análise de conteúdo. As descrevemos didaticamente, a seguir.

\section{Regra 1: Regras claras de inclusão e exclusão nas categorias}

Devem existir regras formais, claras, objetivas e escritas (formalizadas por completo, no que usualmente é chamado "livro de códigos" ou "dicionário") sobre a inclusão e exclusão de determinados conteúdos nas categorias criadas. Em definição, "as regras de uma análise de conteúdo especificam quais os sinais que devem ser classificados e em que categorias. Essas regras são, com efeito, regras semânticas para a linguagem da comunicação a ser analisada." (JANIS, 1982 [1949], p. 55)

Por mais intuitivo que possa parecer, quais são os limites de dada categoria devem ser claros e formalizados. Dito de outra forma, a primeira regra é quase tautológica: é absolutamente necessária a própria existência de regras (regras para inclusão de cada conteúdo em cada categoria). A ausência desta regra leva ao problema de informações de inclusão/exclusão incompletas ou insuficientes. Às vezes estas regras existem, mas são dúbias, o que gera erros de classificação e interpretação dos dados. Estes problemas estão intimamente relacionados ao problema da objetividade da classificação, como argumentaremos na regra 5.

Derivação natural disto está a necessidade de publicização aos leitores das regras de inclusão utilizadas. Se a primeira regra do clube da luta é não falar sobre o clube da luta as coisas são opostas quando se trata de análise de conteúdo (ou qualquer procedimento científico em geral). Em fato, você precisa falar sobre suas categorias. O significado destas categorias deve ser explicitado aos leitores. Não adianta os ter durante a coleta, mas não deixar claro no paper, artigo ou outra produção intelectual. Este é, também, um elemento importante para propiciar a eventual replicabilidade ${ }^{20}(\mathrm{KING}, 1995,2015)$ do estudo, característica central na definição do que é ciência.

Podemos exemplificar a partir da pesquisa de Lasswell (1982b [1949]), em que este queria detectar se os jornais britâncios, durante a segunda guerra mundial, apresentavam argumentos favoráveis ou desfavoráveis à Alemanha Nazista, à União Soviética e aos Estados Unidos. Para isso, o autor precisou definir o que considerava posições favoráveis ou desfavoráveis. Uma regra de inclusão/exclusão falha seria aquela que não explicitasse a compreensão ou definição exata que os analistas tinham por posições favoráveis ou desfavoráveis ao governo. Lasswell, no entanto, gasta espaço considerável de seu artigo discutindo sua definição e apresenta oito tipos de testes lógicos (elementos de caracterização de comportamentos) diferentes que indicavam se a mensagem poderia ou não incorrer naquilo que procuravam classificar. Assim, ele deixa claros a definição e os limites de suas categorias.

Regra 2: As categorias precisam ser mutuamente excludentes (exclusividade)

O conteúdo não pode, sob nenhuma hipótese, ser passível de classificação em mais de uma categoria. Isso remete à regra número 1 , que diz que a definição das categorias deve ser clara. O que está em uma categoria, não pode estar em outra. Um determinado conteúdo não pode ser passível de ser classificado em

20 Replicabilidade é a característica de uma pesquisa que possa ser reproduzida ou duplicada por outros pesquisadores, em outras condições. Ver King $(1995,2015)$. 
uma ou outra categoria, a depender da interpretação do analista. As categorias não podem ter elementos que se sobreponham ou sejam redundantes, que possibilite que as mensagens (conteúdo) se encaixem em uma ou outra categoria. A quebra desta regra levaria à ausência de confiabilidade (regra 5). Como lembramos na regra 1 , estas regras precisam ser muito bem definidas.

Klaus Krippendorff define que "exclusividade mútua se refere à habilidade de uma linguagem de dados fazer claras as distinções entre o fenômeno a ser codificado. Nenhuma unidade de análise pode se encaixar em duas ou mais categorias." (KRIPPENDORFF, 2004, p. 132) ${ }^{21}$. Já Kimberly Neuendorf argumenta que "deve existir apenas uma categoria apropriada para cada unidade codificada. Se existir a possibilidade de múltiplas categorias, então estas devem ser divididas em medidas separadas." (NEUENDORF, 2002, p. 119) 22

Vamos nos valer do exemplo dado pela própria Neuendorf em sua obra. Digamos que você queira descobrir as estratégias de promoção de determinados produtos (Neuendorf exemplifica a partir de web banners, mas o argumento pode ser utilizado para qualquer outro meio). Para isso, criou as seguintes categorias: i) sem estratégia de promoção; ii) mais informacional do que emocional; iii) mais emocional do que informacional; iv) demonstração de produto; v) solução de problemas; vi) reputação da marca; vii) comparação de produtos. Bom, esta é uma categorização ruim, pois as categorias não são mutuamente excludentes. Uma dada propaganda poderia facilmente ser codificada em uma ou mais das categorias listadas, ao mesmo tempo. Um modo mais correto neste caso, argumenta a autora, seria coletar cada uma destas informações em variáveis separadas (presença ou ausência de cada um dos indicadores) e depois montar estes "tipos", a partir dos resultados empíricos..

Sobre os problemas fundamentais gerados por categorias não exclusivas, vale a pena conferir a acidez de Krippendorff:

É difícil solucionar uma situação na qual duas ou mais categorias carecem de exclusividade mútua. A bem intencionada prática de adicionar categorias como "ambíguo" ou "aplicável a duas ou mais categorias" a um conjunto de categorias com sobreposição não altera a indistinção básica das categorias; isto incentiva a indecisão de parte dos codificadores e raramente rende uma variável suficientemente confiável. Quando uma análise de conteúdo usa tais categorias, revela mais sobre suas próprias concepções obscuras do que sobre as propriedades do texto, e enviesam seus resultados de pesquisa em direção a fenômenos facilmente descritíveis. Não existe nenhum remédio verdadeiro para concepções ambíguas. (KRIPPENDORFF, 2004, p. 132, tradução livre) $)^{23}$

Um problema correlato, mas distinto, que pode ocorrer na pesquisa empírica é que o analista se depare com a presença de mais de um conteúdo em uma mesma mensagem. Por exemplo, imagine a análise de discursos de um político. As falas usualmente têm um tema central, mas também temas secundários. Nosso hipotético candidato pode falar sobre uma proposta de política pública (social, econômica etc) e aproveitar para dizer que seu adversário foi ou vai ser contra tais projetos. O analisa, neste caso, poderá ficar na dúvida se classifica como "proposta de política pública" ou como "ataque aos adversários". A solução é a criação de

${ }^{21}$ No original: "Mutually exclusive refers to the ability of a data language to make clear distinctions among the phenomena to be recorded. No recording unit may fall between two categories or be represented by two distinct data points."

${ }^{22}$ No original: "There should be only one appropriate code for each and every unit coded. If there is the possibility of multiple codes, then these ought to be broken down into separate measures."

${ }^{23}$ No original: "It is more difficult to resolve a situation in which two or more categories lack mutual exclusivity. The well-intended practice of adding categories such as "undecidable" "ambiguous" or "applicable to two or more categories" to sets of categories with overlapping meanings does not alter the categories' fundamental indistinctiveness; it invites indecision on the part of coders and rarely renders a variable sufficiently reliable. When content analysts use such categories, they reveal more about their own unclear conceptions than about the properties of texts, and they bias their research results in the direction of easily describable phenomena. There is no real remedy for ambiguous conceptions" 
outra variável, nomeada, por exemplo, “Tema_2", para obter os temas secundários ${ }^{24}$. A criação de variáveis suplementares é muitas vezes necessária para contemplar situações assim e é aceitável. Mas é importante você notar a diferença. Neste caso, não se trata de categorias dúbias, criadas de forma errada (que o analista fique em dúvida se cabe em uma ou em outra), mas de dar solução para uma característica plural da mensagem.

Regra 3: As categorias não podem ser muito amplas. Ou: não coloque coisas diferentes no mesmo saco (Homogeneidade)

Se as categorias devem ser mutuamente excludentes (regra 2), outra regra é que as categorias devem ser estritas, homogêneas. Isto é, elas não devem ser tão amplas ao ponto de serem capazes de abarcar coisas muito diferentes em uma mesma categoria, sob pena de não ter significado prático para o estudo.

Aqui, a definição do metodólogo Kenneth Bailey é essencial para resumir tanto esta quanto a regra anterior:

Nós geralmente procuramos minimizar a variância dentro do grupo, enquanto maximizamos a variância entre grupos. Isto significa que nós organizamos um conjunto de características em grupos, para que cada grupo seja tão diferente quanto possível de todos os outros grupos, mas cada grupo seja internamente homogêneo quanto possível. Ao maximizar ambos, homogeneidade intra-grupo e heterogeneidade entre-grupos, nós criamos grupos que são tão distintos (não sobrepostos) quanto possível, com todos os membros dentro de um grupo sendo tão iguais quanto possível. (BAILEY, 1994, p. 1, tradução livre $)^{25}$

A citação de Bailey nos diz, fundamentalmente, que, ao mesmo tempo que as categorias devem ser distintas entre si, não podendo se confundir, os conteúdos pertencentes a cada categoria devem ser próximos, similares.

Vamos a um exemplo? Imagine que você está analisando as mensagens transmitidas pelos candidatos durante as eleições. Pode ser emitidas nas propagandas televisivas, nas mídias sociais, em palanques ou onde for. Você quer saber sobre o que eles falam durante a campanha eleitoral e para isso criou (apenas) quatro grandes categorias: policy (propostas de políticas públicas), construção da própria imagem, campanha negativa (ataques a adversários) e agenda (divulgação de eventos etc). Verificando os resultados, você descobre que todos falaram mais sobre propostas de políticas públicas (policies) e em níveis iguais. Pronto, só isso. E agora? Por você ter criado uma categoria ampla demais (propostas de políticas), com coisas distintas no mesmo agrupamento, você perdeu os detalhes que poderiam interessar. Neste caso, teria sido mais pertinente dividir esta categoria em políticas econômicas, sociais e por aí vai, conforme pertinente ${ }^{26}$. Assim você poderia saber se o candidato A falou mais de economia, enquanto o B mais de saúde e educação, por exemplo.

Regra 4: as categorias devem contemplar todos conteúdos possiveis, e "outro" precisa ser residual (exaustividade)

Depois de criadas as categorias, é usual a criação de uma categoria "outro". Por mais precisas que

${ }^{24} \mathrm{Na}$ hora de rodar os testes estatísticos dos dados, estas devem ser tratadas como duas variáveis distintas (tema principal e tema secundário, neste exemplo). Agregá-las, de modo que o total ultrapasse 100\%, implicaria em prejuízos lógicos à compreensibilidade da comparação e da pesquisa.

${ }^{25}$ No original: "we generally seek to minimize within-group variance, while maximizing between-group variance. This means that we arrange a set of entities into groups, so that each group is as different as possible from all other groups, but each group is internally as homogeneous as possible. By maximizing both within-group homogeneity and between-group heterogeneity, we make groups that are as distinct (nonoverlapping) as possible, with all members within a group being as alike as possible."

${ }^{26}$ Em fato, o uso de subgrupos de categorias é a abordagem mais apropriada, uma vez que te permite um grau maior de mensuração e, se for o desejo para a pesquisa, a posterior agregação em categorias principais. 
sejam suas categorias, sempre há algum conteúdo que não se encaixa em nenhuma - para isto serve esta categoria. Contudo, ela precisa ser residual, isto é, apenas sobras. Uma categoria "outro" ${ }^{27}$ (ainda que contenha material muito disperso entre si) que rivalize com demais categorias de conteúdo indica problemas na criação e existência das suas categorias de classificação (regras 1, 2 e 3).

Se há muitos conteúdos que não se encaixam em nenhuma categoria, então estas categorias talvez estejam erradas. Dito de outro modo, as categorias criadas precisam esgotar ${ }^{28}$ o conteúdo que você está analisando. A esta regra os teóricos dão o nome formal de "exaustividade". Novamente podemos recorrer às palavras de Bailey:

As classes formadas precisam ser tanto exaustivas quanto mutuamente exclusivas. Isto significa que se
existem N casos para serem classificados, deve haver uma classe apropriada para cada um destes
(exaustividade), mas apenas uma classe correta para cada, com nenhum caso sendo membro de duas
classes (exclusividade mútua). Assim, deve haver uma classe (mas apenas uma) para cada um dos N
casos. (BAILEY, 1994, p. 3 , tradução livre, grifos no original)

O que o autor chama "classes", ou mesmo tratou por "grupos" anteriormente, evidentemente, são as categorias com as quais estamos lidando. Perceba que a citação diz respeito tanto à regra número 2, quanto à 4, dada que estas questões estão profundamente imiscuídas.

Vamos a um exemplo sobre exaustividade. Digamos que você queira categorizar os discursos dos deputados federais que votaram na admissibilidade do processo de impeachment contra a presidente Dilma Rousseff, em abril de 2016. Neste exemplo, seu interesse de pesquisa era saber a natureza dos argumentos proferidos no momento do voto. Você criou suas categorias antes, a partir do que já sabia previamente (outros estudos nos quais você se baseou, sobre outras votações). Você sabia, então, que os discursos poderiam ter duas grandes naturezas argumentativas: razões técnicas (jurídicas) ou políticas. Você até dividiu estas duas razões em subgrupos, para captar bem o cenário. Criou, por exemplo, categorias para crise econômica, crise política, corrupção etc. Mas, no momento da votação, como foi vastamente noticiado, uma parcela considerável dos deputados proferiu o voto dedicando-o aos próprios familiares ("pelos meus filhos": "pela minha neta" etc). Sua categorização, neste caso, não foi exaustiva, pois não previa "valores morais", categoria na qual estes discursos poderiam se enquadrar. Neste caso hipotético, sua categoria "outro" provavelmente teria superado as de razões técnicas ou mesmo as de razões políticas, indicando existir um problema com a categorização.

Neste exemplo, nós já sabemos o resultado geral (as citações à família) antes do começo da classificação, de modo que podemos ajustar e adequar as categorias. Mas, muitas vezes em estudos empíricos de análise de conteúdo, talvez você só descubra um fenômeno como este no decorrer da coleta de dados. No caso de decidir, já com a coleta em andamento, pela criação de uma nova categoria pois as anteriores não davam conta de um tipo de mensagem específica, é preciso rever e ajustar o conteúdo já classificado anteriormente, para que metade do banco de dados não seja classificado com uma regra e outra parte com outra regra.

\footnotetext{
${ }^{27}$ Vale aqui o registro de abordagem feita por Kaplan e Goldsen (1982, p. 79) com a utilização, além da categoria “outro", da categoria "ininteligível”, para distinguir o que efetivamente era outro tipo de conteúdo e o que era conteúdo que não pôde ser acessado ou compreendido. Embora tal abordagem não esteja em voga atualmente, a consideramos altamente válida.

${ }^{28}$ Não é propriamente uma regra, mas igualmente importante: quanto menos categorias, melhor para proceder com as análises, especialmente em termos de testes estatísticos. Trabalhar com mais de 10 categorias potencialmente inviabiliza a compreensão de um comportamento lógico do objeto estudado. É preciso, portanto, encontrar um ponto de equilíbrio.

${ }^{29}$ No original: "the classes formed must be both exhaustive and mutually exclusive. This means that if $N$ persons are to be classified, there must be an appropriate class for each (exhaustivity), but only one correct class for each, with no case being a member of two classes (mutual exclusivity). Thus, there must be one class (but only one) for each of the N persons."
} 
Regra 5: Objetividade, sem subjetivismos ("confiabilidade")

Esta não é uma regra para criação de categorias, mas para a prática de classificação ${ }^{30}$, como trabalhar com estas - e está intimamente relacionada às demais regras, especialmente a primeira.

A ciência - verdadeira ciência - é um campo onde não se permite achismo. Se algum elemento está sujeito a classificação em categorias diferentes a depender da subjetividade do analista, então estas categorias não estão definidas de forma apropriada (ver regras 1, 2, 3 e 4). A esta ideia os metodólogos da análise de conteúdo chamam "confiabilidade"

A importância da confiabilidade repousa na segurança de que os dados obtidos são independentes do evento de mensuração, do instrumento ou da pessoa. Os dados confiáveis, por definição, são aqueles que permanecem constantes ao longo das variações no processo de medição. (...) Em que medida os resultados de uma análise de conteúdo são independentes do analista específico - isto é, em que medida outros analistas chegariam ao mesmo resultado? (KAPLAN \& GOLDSEN, 1982 [1949], p. 77)

E ainda:

O primeiro requisito de uma técnica que se propõe a descrever qualquer conjunto de características é o de que os resultados tenham alto grau de confiabilidade, isto é, que observadores diferentes relatem a mesma coisa. No caso dos resultados da análise de conteúdo, a confiabilidade pode ser atestada pela determinação do grau de correlação entre as frequências obtidas quando diferentes analistas estudam o mesmo conteúdo independentemente. [...] Diz-se que um instrumento de mensuração tem "validade" 32 se mede o que efetivamente se propõe a medir; diz-se que este instrumento possui "confiabilidade" se apresenta os mesmos resultados consistentemente. (JANIS, 1982 [1949], pp. 54-56)

Em resumo, a regra da objetividade é que os mesmos dados devem ser passíveis de classificação igual por analistas diferentes. A replicação de uma pesquisa é elemento central em qualquer pesquisa científica e,

\footnotetext{
${ }^{30}$ Para quem estiver interessado em classificações, em sentido mais amplo (não pela criação manual de categorias que tratamos aqui), em especial métodos automatizados de classificação, poderá encontrar conteúdo interessante em Figueiredo Filho, Silva e Rocha, 2012 (sobre clusters), Figueiredo Filho et al, 2013 (sobre análise de componentes principais) e Figueiredo Filho et al, 2014 (sobre análise fatorial).

${ }^{31} \mathrm{O}$ método mais rigoroso para coleta e classificação dos dados (embora às vezes não utilizado por falta de recursos humanos nas pesquisas), como usado por Lasswell e colegas, é que dois ou mais analístas diferentes (que não se comuniquem) codifiquem o mesmo conteúdo separadamente. Após isso, podem ser feitos testes para verificar o grau de confiabilidade (congruência) das classificações. Lombard, Snyder-Duch \& Bracken (2002) argumentam que a simples porcentagem de acordância/discordância entre os codificadores (como às vezes é relatado em certas pesquisas) é insuficiente, apontando para alternativas de testes estatísticos destinados a este fim. Sobre o nível de confiabilidade, os autores reportam que coeficientes acima de .90 são aceitáveis em todas situações e, abaixo disto mas acima de .80 aceitáveis somente em alguns estudos. Softwares e pacotes estatísticos (como o SPSS, mas não apenas) fornecem recursos específicos destinados a verificar o grau de consistência do conteúdo classificado por distintos codificadores. Em estudos mais rigosos, do ponto de vista metodológico, é obrigatório reportar no artigo o valor dos testes de confiabilidade. 32 "Validade" é outro conceito fundamental na pesquisa científica, mas não parte do recorte principal deste artigo. Como definido por Janis, se refere à se o indicador utilizado realmente retrata aquilo que se está analisando. Por exemplo, Robert Dahl, em seu clássico livro, propõe utilizar liberdade de se opor ao governo e oportunidade de participar do mesmo para medir distintos graus de democracia (DAHL, 1997 [1971]). Se por outro lado, hipoteticamente, alguém se propuser a medir democracia apenas por um indicador de liberdade econômica, este não será um instrumento "válido", pois não mede inteiramente aquilo que se propõe. Para uma profunda discussão sobre o conceito de validade aplicado à análise de conteúdo, em relação às múltiplas leituras possíveis que um dado analista pode fazer de determinado texto (e como resolver isso), recomendamos fortemente a leitura de Janis (1982 [1949]).
} Para uma sintese recente sobre esta questão, veja Adcock \& Collier (2001). 
se esta replicação não é possível por ser subjetiva, ela simplesmente não se enquadra no conceito de ciência. ${ }^{33}$

Então, fica como lição de vida para quem se proponha a fazer ciência (seja política, seja da comunicação, seja social): banir a palavra subjetivo de vossas vidas. Como nos ensina Kaplan e Goldsen (1982 [1949]), se algo é subjetivo, então não é científico. Ponto, parágrafo.

\section{Uma questão: o equilíbrio entre comparabilidade e adaptabilidade}

Esta não é uma regra, mas um ponto de tensão, sempre a ser resolvido: qual o ponto de equilíbrio entre adaptabilidade e comparabilidade? Isto é, seguir um modelo de categorias já utilizado pela literatura (garantindo a comparabilidade) ou adaptar/criar categorias específicas, para o estudo que está sendo conduzido?

Outros vieram antes de você e provavelmente já conduziram pesquisas em sua área, de modo que já existem classificações próximas ao seu objeto de estudo. Comparabilidade entre distintas pesquisas é um elemento central no processo científico. Para isso, é necessária a manutenção de um coração mais ou menos similar de categorias. Lembre-se que seu estudo terá mais visibilidade se seus resultados puderem ser comparados com demais estudos (KING, 1985, 2015). A incomunicabilidade de pesquisas que, tendo o mesmo objeto, utilizam tipologias distintas é um problema recorrente em diversas áreas e linhas de pesquisa da ciência política.

No entanto, a necessidade de comparabilidade não deve limitar seu escopo de pesquisa. Cada pesquisa tem seus objetivos e o conjunto de categorias criado deve responder à questão de pesquisa de seu autor. Simplesmente seguir um modelo pronto mesmo quando ele não se adequa ou não atende às necessidades da pesquisa sendo proposta é atitude pouco imaginativa ou propositiva.

Se a categorização deve, de fato, atender aos interesses da questão de pesquisa do investigador, um acordo mínimo com a literatura é imprescindível para que as pesquisas possam ser comparáveis. Se, por exemplo, na antropologia isto não seria um problema (já que cada objeto é único e as conclusões só são válidas para aquele caso), um dos objetivos da ciência política é a extrapolação de suas conclusões, isto é, a formulação de explicações gerais para grandes fenômenos. Para que isto ocorra, é fundamental que os estudos possam dialogar. Se físicos não teriam este tipo de problema - dificilmente cada um deles categorizaria um átomo de formas diferentes - os cientistas sociais precisam passar por esta etapa de acordância metodológica entre os pares. Como diz Howard Becker:

A ciência só pode fazer progresso quando os cientistas concordam quanto ao aspecto de um problema e de sua solução - isto é, quando empregam categorias de uso consagrado. Se cada um tiver uma idéia diferente sobre os tipos de entidades que o mundo é composto, sobre os tipos de perguntas e respostas que fazem sentido, cada um estará realizando uma coisa diferente, e isso não constituirá coisa alguma. (BECKER, 2007, p. 117)

É preciso, portanto, um equilíbrio delicado entre a manutenção de categorias (a fim da comparabilidade com estudos da área) e adaptação de categorias para pesquisas específicas, quando necessárias. Mas é preciso, como ocorre na boa ciência, construir a partir do já existente.

\footnotetext{
${ }^{33}$ Esta é uma perspectiva muito estrita de ciência, adotada aqui. Outras perspectivas são possíveis, mas tal discussão epistemológica não é o foco deste estudo. Tais concepções relativísticas de ciência são, a partir da perspectiva adotada (e amplamente referendada pela corrente majoritária da comunidade científica), equivocadas.
} 
6. CONSIDERAÇÕES FINAIS

Neste artigo metodológico sintetizamos os aspectos básicos do que é análise de conteúdo e como proceder para criar categorias funcionais para aplicação neste tipo de abordagem. Nos baseamos nos criadores da metodologia, Harold Lasswell e seus colegas norte-americanos, bem como em metodólogos contemporâneos, ressaltando sua contribuição central para o campo.

Acreditamos que este artigo se apresenta como uma ferramenta didática útil, especialmente para pesquisadores em fase inicial que possuam o interesse pela aplicação da análise de conteúdo em suas pesquisas. Resumimos em cinco aspectos principais os elementos fundamentais para a criação e classificação de categorias.

Em termos simples: a) é preciso existir regras claras sobre os limites e definição de cada categoria; b) as categorias devem ser mutuamente exclusivas (o que está em uma categoria, não pode estar em outra); c) as categorias devem ser homogêneas (não ter coisas muito diferentes entre si, no mesmo grupo); d) é preciso que as categorias esgotem o conteúdo possível (não sobrem conteúdos não conteúdos que não se encaixem em alguma categoria); e) é preciso que a classificação seja objetiva, possibilitando a replicação do estudo.

Estas mesmas regras lógicas valem, também, para a criação de categorias e a classificação de atributos de quaisquer objetos de pesquisa (não apenas "mensagens"), em termos mais gerais, para outros estudos, ainda que não aplicados à análise de conteúdo. Ou seja, ainda que o leitor discorde da perspectiva teórico-metodológica adotada na primeira parte do artigo, poderá fazer uso das regras sintetizadas na segunda parte para adequadamente conduzir suas pesquisas.

Estes são os aspectos fundamentais da classificação e categorização em análise de conteúdo clássica, construída manualmente. Há muitos outros tópicos e problemáticas em aberto nesta seara, sobre os quais não tocamos. Nos últimos anos, tem ocorrido verdadeira revolução na área. Com o desenvolvimento do big data e técnicas de data mining novas aboragens têm surgido para análise de conteúdo automatizada. Por exemplo, Gary King, de Harvard, em dois estudos (HOPKINS \& KING, 2010; KING, PAN \& ROBERTS, 2013), criou um método para coleta e classificação automatizada dos textos. Há uma longa lista de estudos que propõem novas abordagens a partir de métodos computacionais para análise de textos, ou mesmo abordagens hibridas (LEWIS, ZAMITH, HERMIDA, 2013).

A análise de conteúdo é uma técnica vastamente utilizada nas ciências sociais que, quando feita corretamente, tem o potencial de revelar muitos aspectos sobre os objetos analisados. Apesar de ter sido desenvolvida para estudos de comunicação social - e historicamente utilizada nestes - a metodologia também pode ser aplicada em uma longa série de distintos estudos. Mas, para isto, o pesquisador deve estar imbuído de rigor metodológico e, nas palavras de Harold Lasswell, “é essencial que a análise seja conduzida com espírito científico e mediante o emprego de procedimentos objetivos" (LASWEELL, 1982b [1949], p. 165).

\section{Referências bibliográficas}

ADCOCK, R.; COLLIER, D. 2001. Measurement Validity: A Shared Standard for Qualitative and Quantitative Research. The American Political Science Review, 95(3), 529-546.

AGGIO, C. 2015. Os candidatos ainda evitam a interação? Twitter, Comunicação Horizontal e Eleições Brasileiras. ECompós (Brasília), v. 18, p. 122.

ALDÉ, A.; MENDES, G. G. ; FIGUEIREDO, M. 2007. Tomando Partido: Imprensa e política nas eleições 
de 2006. Politica \& Sociedade, v. 10, p. 20-28.

BAKHTIN, M. 2006. Marxismo e filosofia da linguagem. 12a Edição. São Paulo: Hucitec

BAILEY, K. D. 1994. Typologies and Taxonomies: An Introduction to Classification Techniques. Sage Series on Quantitative Applications in the Social Sciences, Thousand Oaks, California: Sage.

BARBERIA, Lorena Guadalupe; GODOY, Samuel Ralize de; BARBOZA, Danilo Praxedes. 2014. Novas perspectivas sobre o 'calcanhar metodológico': o ensino de métodos de pesquisa em Ciência Política no Brasil. Teoria \& Sociedade. $n^{\circ} 22.2$.

BARDIN, L. 2011 [1977]. Análise de conteúdo. São Paulo: Edições 70.

BECKER, Howard S. 2007. Segredos e truques da pesquisa. Rio de Janeiro: Jorge Zahar Ed.

BERELSON, B. 1952. Content analysis in communication research. Glencoe: The Free Press.

BURNS, R.; BURNS, R. 2008. Business Research Methods and Statistics Using SPSS. London: SAGE Publications Ltd.

BRAGA, S.; NICOLÁS, M. A.; BECHER, A. R. 2013. Clientelismo, internet e voto: personalismo e transferência de recursos nas campanhas online para vereador nas eleições de outubro de 2008 no Brasil. Opinião Pública. Campinas v. 19, p. 168-197.

BRAGA, S. ; ROCHA, L. C.; CARLOMAGNO, M. C. 2015. A internet e os partidos brasileiros. Cadernos Adenauer. São Paulo, v. XVI, p. 47-74.

CAMPOS, L.A. 2014. A identificação de enquadramentos através da análise de correspondências: um modelo analítico aplicado à controvérsia das ações afirmativas raciais na imprensa. Opin. Publica, vol.20, n.3. CAREGNATO, R. C. A.; MUTTI, R. 2006. Pesquisa qualitativa: análise de discurso versus análise de conteúdo. Texto Contexto Enferm, Florianópolis, Out-Dez; 15(4): 679-84.

CARVALHO, Rafiza Luziani Varão Ribeiro. 2012. Harold Lasswell e o Campo da Comunicação. Tese de doutorado. Brasília: Universidade de Brasília.

CERVI, E. 2014. Análise de dados categóricos em ciência política. Curitiba: Universidade Federal do Paraná.

2011. Uso do HGPE como recurso partidário em eleições proporcionais no Brasil: um instrumento de análise de conteúdo. Opinião Pública, v. 17, p. 106136.

CERVI, E.U.; MASSUCHIN, M.G. 2013. Metodologia quantitativa em pesquisas sobre cobertura jornalística. Revista FAMECOS, v. 20, p. 840-865.

CERVI, E.U.; MASSUCHIN, M.G. ; TAVARES, C.Q. 2012. Agenda da mídia, dos políticos e do público na campanha eleitoral de 2010. Revista Debates (UFRGS), v. 6, p. 237-261.

DAHL, R. 1997 [1971]. Poliarquia: participação e oposição. São Paulo: EDUSP.

DOWNE-WAMBOLDT, B.. 1992. Content analysis: Method, applications, and issues.

Health Care for Women International, 13:3, 313-321.

FERES JUNIOR, J. 2016. Em defesa das valências: uma réplica. Revista Brasileira de Ciência Política, $\mathrm{n}^{\circ} 19$. Brasília, janeiro - abril de 2016, pp. 277-298.

FIGUEIREDO, M; ALDÉ, A; DIAS, H; JORGE, V.L. 1997. Estratégia de persuasão eleitoral: uma proposta metodológica para o estudo da propaganda eleitoral. Opinião Pública, Campinas, v. IV, n.3, p. 109-120.

FIGUEIREDO, M.; ALDÉ, A.; MENDES, G. G. 2007. Imprensa e Eleições Presidenciais: Natureza e Consequência da Cobertura das Eleições de 2002 e 2006. In: Venício A. de Lima. (Org.). A Mídia nas Eleições de 
2006. Sâo Paulo: Editora Fundação Perseu Abramo, p. 65-87.

FIGUEIREDO FILHO, D.B.; PARANHOS, R.; ROCHA, E.C. da; Da SILVA JR, J.A.; MAIA, R.G. 2013. Análise de componentes principais para construção de indicadores sociais. Rev. Bras. Biom., São Paulo, v.31, n.1, p.61-78.

FIGUEIREDO FILHO, D.B.; ROCHA, E.C. da; PARANHOS, R.; SILVA, A.H.; SILVA JR., J.A.; OLIVEIRA, L.E.; ALVES, D.P. 2014. Análise fatorial garantida ou o seu dinheiro de volta: uma introdução à redução de dados. Revista Eletrônica de Ciência Política, vol. 5, n. 2.

FIGUEIREDO FILHO, D.B.; SILVA JÚNIOR, J.A. da; ROCHA, E.C. da. 2012. Classificando regimes políticos utilizando análise de conglomerados. Opinião Pública, Campinas, vol. 18, nº 1, p. 109 - 128 GIBSON, R., WARD. S. 2000. Proposed methodology for studying the function and effectiveness of party and candidate web sites. Social Science Computer Review. London, v. 18 n. 3, p. 301-319.

HOPKINS, D. J.; KING, G. 2010. A Method of Automated Nonparametric Content Analysis for Social Science. American Journal of Political Science, Vol. 54, No. 1, Pp. 229-247

ITUASSU, A.; LIFSCHITZ, S. 2015. Temas e Mídia em \#Eleições2014: Twitter, opinião pública e comunicação política no contexto eleitoral brasileiro. E-compós, Brasília, v.18, n.2, maio/ago. 2015.

JACKSON, N.; LILLEKER, D. 2011. Microblogging, Constituency Service and Impression Management: UK MPs and the Use of Twitter. The Journal of Legislative Studies, 17:1, 86-105.

JANIS, I. L. 1982 [1949]. O problema da validação da análise de conteúdo. In: LASSWELL, H; KAPLAN, A. A linguagem da política. Brasília: Editora da Universidade de Brasília.

KAPLAN, A.; GOLDSEN, J. M. 1982 [1949]. A confiabilidade das categorias de análise de conteúdo. In: LASSWELL, H; KAPLAN, A. (org.) A linguagem da política. Brasília: Editora da Universidade de Brasília. KING. G. 1995. Replication, Replication. PS: Political Science \& Politics 28: p. 444-452.

KING, G. 2015. Replicação, replicação. Revista Eletrônica de Ciência Política, vol. 6, n. 2, 2015

KING, G.; PAN, J. \& ROBERTS, M. E. 2013. How censorship in china allows government criticism but silences collective expression. American Political Science Review, v. 107, n. 2, p. 1-18.

KRIPPENDORFF, K. 2004. Content analysis : an introduction to its methodology . 2nd ed. Thousand Oaks, California: Sage Publications, Inc.

LASSWELL, H. 1982a [1949]. Por que ser quantitativista? In: LASSWELL, H; KAPLAN, A. (org.) A linguagem da política. Brasília: Editora da Universidade de Brasília.

LASSWELL, H. 1982b [1949]. A deteç̧ão da propaganda e a justiça. In: LASSWELL, H; KAPLAN, A. (org.) A linguagem da política. Brasília: Editora da Universidade de Brasília. LEITE, F.; CODATO, A. 2013. Autonomização e institucionalização da Ciência Política brasileira: o papel do sistema Qualis-Capes. Agenda Política, v. 1, p. 1-21-21.

LEITE, F. 2010. Posições e divisões na Ciência Política brasileira contemporânea: explicando sua produção acadêmica. Revista de Sociologia e Política (Online), v. 18, p. 149-181.

2015. O campo de produção da Ciência Política brasileira contemporânea: uma análise histórico-estrutural de seus princípios de divisão a partir de periódicos, áreas e abordagens. Tese de doutorado. Curitiba: Universidade Federal do Paraná.

LEWIS, S.C ;ZAMITH, R.; HERMIDA, A. 2013. Content Analysis in an Era of Big Data: A Hybrid Approach to Computational and Manual Methods. Journal of Broadcasting \& Electronic Media, 57:1, 34-52

LILLEKER, D.; KOC-MICHALSKA, K. 2013. Online Political Communication Strategies: MEPs, E-Representation, and Self-Representation. Journal of Information Technology \& Politics, 10:190-207. 
LOMBARD, M.; SNYDER-DUCH, J.; BRACKEN, C.C. 2002. Content Analysis in Mass Communication Assessment and Reporting of Intercoder Reliability. Human Communication Research, Vol. 28 No. 4, 587-604.

MADEIRA, A.B.; LOPES, M.; GIAMPAOLI, V.; SILVEIRA, J. 2011. Análise proposicional quantitativa aplicada à pesquisa em administração. RAE. São Paulo, v.51 n.4, 396-410.

MESQUITA, L; SILOTTO, G; LUZ, J; HUBERT, P. 2014. Emendas individuais e concentração de votos: uma análise exploratória. Teoria \& Pesquisa, v.23, n.2.

MIGUEL, L.F. 2015. Quanto vale uma valência? Revista Brasileira de Ciência Política, nº17, pp. 165-178. . 2016. Uma resposta. Revista Brasileira de Ciência Política, nº19. Brasília, janeiro - abril de 2016, pp. 299-301.

MINTZ, A. 1982 [1949]. A factibilidade do emprego de amostras na análise de conteúdo. In: LASSWELL, H; KAPLAN, A. (org.) A linguagem da política. Brasília: Editora da Universidade de Brasília. MORAES, R. 1999. Análise de conteúdo. Revista Educação, Porto Alegre, v. 22, n. 37, p. 732.

MOZZATO, A. R.; GRZYBOVSKI, D. 2011. Análise de conteúdo como técnica de análise de dados qualitativos no campo da administração: potencial e desafios. RAC, Curitiba, v. 15, n. 4, pp. 731-747.

NEIVA, Pedro. 2015. Revisitando o calcanhar de aquiles metodológico das ciências sociais no brasil. Sociologia, problemas e práticas, n. ${ }^{\circ} 79$, pp. 65-83.

NEUENDORF, K. 2002. The content analysis guidebook. Thousand Oaks, California: Sage Publications, Inc.

NICOLAS, M.A.; BRAGATTO, R.C.; SAMPAIO, R.C. 2013. Internet and Politics studies in Brazil: mapping the characteristics and disparities of the research field. Brazilian Political Science Review, v. 7, p. 114140.

OLIVEIRA, D. C. 2008. Análise de conteúdo temático-categorial: uma proposta de sistematização. Rev. enferm. UERJ, Rio de Janeiro, 2008 out/dez; 16(4):569-76.

PÊCHEUX, M. 2009. Semântica e discurso: uma crítica à afirmação do óbvio. Campinas: Editora Unicamp.

PIMENTEL, A. 2001. O método da análise documental: seu uso numa pesquisa historiográfica. Cadernos de Pesquisa, n. 114, novembro.

RECUERO, R.; ZAGO, G.; BASTOS, M.T. 2014. O discurso dos \#ProtestosBR: análise de conteúdo do Twitter. Galáxia (São Paulo), Dez 2014, vol.14, no.28, p.199-216.

RIFFE, D.; LACY, S.; FICO, F:G. 2005. Analyzing media messages: using quantitative content analysis in research. Mahwah, New Jersey: Lawrence Erlbaum Associates, Inc. / Taylor \& Francis e-Library.

SAMPAIO, R. C.. 2012. Quão deliberativas são discussões na rede? Um modelo de apreensão da deliberação online. Revista de Sociologia e Política, v. 20, p. 121-139.

SAMPAIO, R.C.; BARROS, S.A.R.; MORAIS, R. 2012. Como avaliar a deliberação online? Um mapeamento de critérios relevantes. Opinião Pública, v. 18, p. 470-489.

SILVA, C. A comunicação partidária online: Os websites num contexto não eleitoral. 2012. Dissertação (Mestrado em Ciência Política) - Universidade de Aveiro.

SILVA, C. R.; GOBBI, B. C., SIMÃO, A. A. 2005. O uso da análise de conteúdo como uma ferramenta para a pesquisa qualitativa: descrição e aplicação do método. Organ. rurais agroind., Lavras, v. 7, n. 1, p. $70-81$. 
SILVA, A. H.; FOSSÁ, M. I. T. 2013. Análise de conteúdo: exemplo de aplicação da técnica para análise de dados qualitativos. 2013. In: IV Encontro de Ensino e Pesquisa em Administração e Contabilidade. Brasília, DF.

SILVA, D. C.; RIBEIRO, R. A.; CARVALHO, T. C. O. 2015. A análise de conteúdo de pronunciamentos oficiais como metodologia interpretativa da política externa brasileira. Revista Eletrônica de Ciência Política, vol. 6, n. 2, 2015.

SOARES, G.A.D. 2005. O calcanhar metodológico da ciência política no brasil. Sociologia, problemas e práticas, n. ${ }^{\circ} 48,2005$, pp. 27-52.

VACCARI, C. 2008. Italian parties websites in the 2006 elections. European Journal of Communication, v. 23 , n. 1 , p. $9-77$

VILELA, E.; NEIVA, P. 2011. Temas e regiões nas políticas externas de Lula e Fernando Henrique: comparação do discurso dos dois presidentes. Rev. Bras. Polít. Int. 54 (2): 70-96. 